\title{
Behavioural Sleep Disorders across the Developmental Age Span: An Overview of Causes, Consequences and Treatment Modalities
}

\author{
Sarah Lee Blunden \\ Appleton Institute, Central Queensland University, Adelaide, Australia \\ Email: s.blunden@cqu.edu.au
}

Received November 18 ${ }^{\text {th }}$, 2011; revised December 21 ${ }^{\text {st }}$, 2011; accepted January $19^{\text {th }}, 2012$

\begin{abstract}
Behavioural sleep problems, that is, sleep problems that do not have a physiological aetiology, but rather a behavioural or psychological aetiology, are reported in between $20 \%-40 \%$ of children and adolescents. These sleep disorders are categorised as Behavioural Insomnia of Childhood (BIC) in the International Classification of Sleep Disorders. BIC can result in short sleep duration and poor quality sleep and can have wide ranging effects on mental and physical health, cognitive and social functioning and development in infants, pre-schoolers, school aged children and adolescents. Each age group have a particular set of behaviourally based sleep disorders. This paper presents a broad overview of BIC and covers essential information about these sleep disorders, their aetiologies, effects on development and non medical treatment modalities.
\end{abstract}

Keywords: Behavioural Sleep Disorders; Behavioural Insomnia; Behavioural Sleep Treatments; Delayed Phase

\section{Introduction}

There is an abundant literature on the consequences of short sleep duration and poor quality sleep on a wide range of negative outcomes in mental and physical health, cognitive and social functioning in young people (Fallone et al., 2001) Sequelae include motor skill deficits (Laureys, 2002); greater emotional liability, increased impulsivity, aggression and hyperactivity (Pearl et al., 2002; Sadeh et al., 2002; Blunden, 2010); increased potential for alcohol and drug abuse in adulthood (Wong et al., 2004); and suicide risk in adulthood (Wojnar, 2009). When left untreated, sleep problems developing during the primary school years can become a persistent problem and equate to poorer health in general (Moore et al., 2002) and sleep difficulties as adults (Chaput, 2008; Buckhault, 2011). Poor sleep in these cases perpetuate poor overall physical health in adults, perhaps mediated by compromised immune function (Vgontzas, 2008), and is more likely among those of lower socioeconomic position (Sekine, 2006). Importantly, short sleep duration is associated with increased risk of overweight and obesity (Carter 2011) due to changes in appetite regulation.

Sleep disorders in the early years can be largely divided into those that have a physiological aetiology (such as sleep related respiratory disorders, parasomnias and periodic limb movement disorder) and those without. The most abundant information regarding the effects of sleep disturbance on daytime function, particularly among children, comes from studies of sleep disordered breathing (SDB). These sleep disorders are prevalent in between $2 \%$ - 15\% of children (Blunden et al., 2003).

However, the most common sleep problems in the early years are overwhelmingly those of a non-physiological aetiology. Most children will experience some degree of transitory and developmentally normal behavioural sleep problem (Stores,
1999; Sadeh et al., 2000), but some children will develop more chronic and persistent sleep problems. In fact, the large majority of sleep problems in young children do not have a physiological aetiology but are behaviourally based (Hiscock et al. 2007).

\section{Defining Behavioural Sleep Disorders}

Behavioural sleep disorders in children are described as Behavioural Insomnia of Childhood (BIC) by American Academy of Sleep Medicine in (AASM 2005), in their International Classification of Sleep Disorders-Second Edition (ICSD-2; 2005; see Table 1). The hallmark feature of BIC is difficulty falling asleep or staying asleep.

The ICSD has documentedBIC as dysomnias. Categorisation of sleep disorders in the ICSD follows the model established by the American Psychiatric Association's Diagnostic and Statistical Manual, (DSMIII-R), to assist in the classification, diagnosis and treatment of sleep problems. The dysomnias described in the second edition of the ICSD are the disorders that produce either difficulty initiating or maintaining sleep or excessive sleepiness and have been further divided into three groups of disorders: intrinsic sleep disorders, extrinsic sleep disorders, and circadian rhythm sleep disorders. The behavioural sleep disorders of interest in this paper are categorised in the ICSD as extrinsic sleep disorders and include those disorders that originate or develop from causes outside of the body. External factors are integral in producing these sleep disorders, and removal of the external factors leads to resolution of the sleep disorder (AASM, 2005). This is not to say that internal factors are not important in the development or maintenance of these sleep disorders. However, the internal factors are unlikely by themselves to produce the sleep disorder without presence of 


\section{S. L. BLUNDEN}

Table 1.

Diagnostic criteria of behavioural insomnia of childhood (ICSD-2).

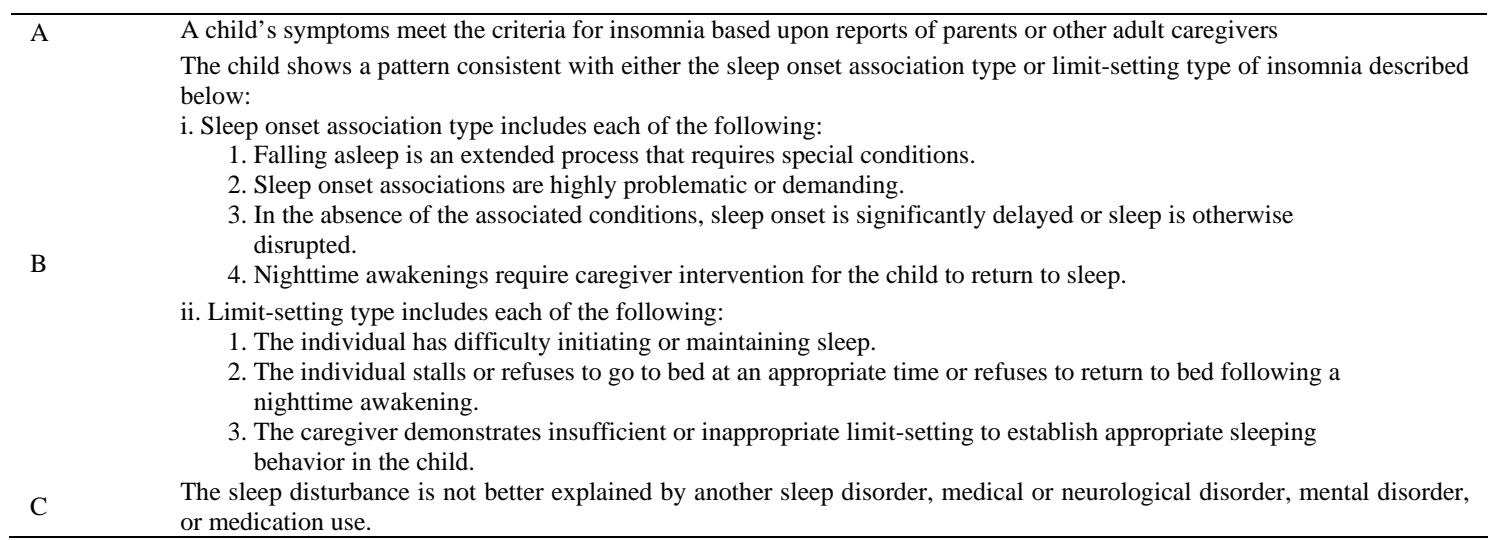

Source: American Academy of Sleep Medicine (2005).

an external factor.

The extrinsic sleep disorders that are considered behavioural for inclusion in this chapter are summarised in Table 2.

\section{Prevalence}

Behavioural sleep disorders are generally a diagnosis of observation or description by third party report and complemented by a complete sleep history (Mindell et al., 1999). Epidemiological estimates of these reported sleep problems in children, as classified by the ICSD, are largely based on age specific cross sectional data and are rarely separated into classifications as listed above. In general however, behavioural sleep problems are common with $20 \%$ - 30\% of infants and toddlers, (Morgenthaler 2006), in 30\% - 40\% of pre-school children (Blader et al., 1997; Owens et al., 1998; Blunden et al., 2005) between 10\% $45 \%$ of pre-pubescent children (Wolfson et al., 2007) and 11\% - 30\% of adolescents (Wolfson, 2003; Carskadon et al., 2004). Despite the wide prevalence range, it is clear that behavioural sleep disorders are common in the paediatric life span. Whether these sleep problems become chronic or significantly problematic is less clear.

\section{Aetiology of Behavioural Sleep Disorders across the Ages}

Evidence would suggest that while certain behavioural sleep disorders are more common in certain age groups (such as a high prevalence of Sleep-onset Association Disorder in young children), all of the behavioural sleep disorders presented above occur across the paediatric spectrum.

\section{Infants and Pre-Schoolers}

In infants and pre-schoolers, the vast majority of sleep problems fall under the classification of either Sleep Association Type or Limit-Setting Type or a combination. In Australia, the sheer prevalence of infant sleep problems poses a substantial population and health burden in the first year of life (Armstrong, 1994). In Sleep Association Type, the child is unable to initiate sleep without the presence of an object or person (e.g., bottle, rocking, feeding, parental presence), thus creating a dependency at sleep onset, during day, evening and overnight sleep initiation or re-initiation. In general, night wakings, viewed as problematic by caregivers because of a child's inability to 'self soothe' (that is, the ability to calm themselves enough to fall asleep alone), fall within the diagnostic category of Behavioural Insomnia of Childhood (BIC), Sleep Onset Association Type. In BIC Limit Setting Type, parents demonstrate difficulties in adequately enforcing bedtime limits resulting often in delayed bedtime and subsequent reduced sleep duration. This is often associated with difficulties adjusting to parenting and can be associated with Adjustment Sleep Disorders (AASM, 2005).

It has been suggested that bedtime resistance and night wakings in childhood are a "regression" in behaviours associated with the neurodevelopmental processes of sleep consolidation and sleep regulation that evolve over the first years of life (Morgenthaler, 2006). However, this 'regression' must take into account psychological factors that may be contributing to sleep problems, notably a potentially normal developmental resistance or adaptation to sleeping alone by children as they become old enough to express their preferences (McKenna, 2000).

Other contributors to these bedtime behavioural problems in young children include temperament-children with more "needy" temperaments require more active parental participation (Weissbluth, 1984; Owens-Stively et al,. 1997)—and culture-cultures with minimal nighttime separation report less overnight wakings and sleep disruption for caregivers (McKenna 2000). Clearly, these factors have a bi-directional relationship with the caregiver and the child's environmental and behavioural variables (Morgenthaler, 2006). Maladjustment to the disruption to caregiver sleep can lead to significant caregiver stress, particularly maternal depression and anxiety, which have been consistently associated with infant sleep problems, even after controlling for known depression risk factors (Hiscock et al., 2007). This is evidenced in the common occurrence of Adjustment Sleep Disorder experienced by parents of young children, when parents adjust to the changes in sleep and daytime routines that are evident with the birth of a new baby.

\section{School Aged Children}

Although children generally achieve sleep consolidation (that is, the ability to achieve a stretch of uninterrupted sleep and to self soothe) by the time they attend school (Mindell et al., 1999), behavioural sleep disorders such as Sleep-onset Association Disorder and Limit Setting Disorder are still commonly re- 


\section{S. L. BLUNDEN}

Table 2.

Common behavioural sleep disorders in children and adolescents according to the ICSD (AASM 2005).

\begin{tabular}{ll}
\hline Inadequate Sleep Hygiene & $\begin{array}{l}\text { Inadequate Sleep Hygieneis a sleep disorder due to the performance of daily living activities that } \\
\text { are inconsistent with the maintenance of good quality sleep and full daytime alertness. } \\
\text { Adjustment Sleep Disorder }\end{array}$ \\
$\begin{array}{l}\text { Adjustment Sleep Disorderrepresents sleep disturbance temporally related to acute stress, } \\
\text { conflict, or environmental change that causes emotional arousal. }\end{array}$ \\
$\begin{array}{l}\text { Insufficient Sleep Syndromeis a disorder that occurs in an individual who persistently fails to } \\
\text { obtain sufficient nocturnal sleep required to support normally alert wakefulness. } \\
\text { Limit-Setting Sleep Disorder }\end{array}$ & $\begin{array}{l}\text { Limit-setting sleep disorderis primarily a childhood disorder that is characterized by the } \\
\text { inadequate enforcement of bedtimes by a caretaker, with the patient then stalling or refusing to go } \\
\text { to bed at an appropriate time. } \\
\text { Sleep-onset Association Disorderoccurs when sleep onset is impaired by the absence of a certain } \\
\text { object or set of circumstances. }\end{array}$ \\
\hline
\end{tabular}

ported (Mindell, 2003). Contrary to younger children, sleep associations in school aged children rarely involve feeding associations but are more likely to include the associations that include the presence of a caregiver (Kushnir, 2011). Developmentally, mild and time-limited nighttime fears are very prevalent in normal development, and most children overcome or outgrow them (Gordon, 2007) but those who do not, are more likely to display bedtime fears and need assistance to settle, often developing Sleep-onset Association Disorder. Sleep problems are an integral part of the clinical picture in children with fears at bedtime as they present with difficulty going to sleep and falling asleep alone, frequent night wakings, and difficulty resuming sleep without assistance. Parental concerns over their child's difficulty in overcoming these fears often result in a child depending on their caregiver to stay with them at sleep initiation or reinitiation. Coupled with this, parental inability to encourage a child to overcome their fears may be compromised, exacerbating the problem.

There is also increasing evidence that sleep hygiene factors, such as excessive media usage at bedtime, and often in the bedroom itself, are also impacting on sleep (Gupta, 1994). Most particularly, these factors are significant in delaying bedtime and can develop into Inadequate Sleep Hygiene Syndrome.

In two studies in pre pubescent school aged children (Owens et al., 1999; Heins et al., 2007), television-viewing practices were associated with bedtime resistance and bedtime fears and sleep onset delay resulting in insufficient sleep. In fact, all media, such as computer games, mobile phones and computers are equally as problematic when they interfere with sleep health (Gupta, 1994). Reducing media exposure at bedtime should be assertively emphasized by parents and caregivers of school aged children. That is, caregivers may need to set limits regarding media usage. In fact, in the study by Owens et al. (1999), despite overall close monitoring of television-viewing habits, one quarter of the parents reported the presence of a television set in the child's bedroom. Limit setting would appear to be a significant contributing factor to Inadequate Sleep Hygiene Disorders in this age group. This is of concern given that evidence suggests that extensive television viewing during middle school and adolescencemay contribute to the development of sleep problems by earlyadulthood (Johnson, 2004).

\section{Adolescents}

In adolescents, based on the published literature, the most common behavioural sleep disorders appear to be Inadequate Sleep Hygiene, Insufficient Sleep Syndrome and Limit Setting Disorders.
Many contributing factors during the teenage years make increasing demands on an adolescent's evening activities that compete for sleep time. These demands include social activities, sports, part-time employment, and increased academic workloads (Wolfson, 2003). Similar to the younger age groups, there is considerable evidence that increased computer or mobile telephone activity at night, (Carskadon et al., 1998) and the presence of televisions and computers in the bedrooms have a significant delaying effect on sleep onset in the age group (Johnson 2004; Van den Bulck 2004; Olds et al., 2006). Given the biological tendency in adolescents for a delayed sleep phase due to a delay in melatonin secretion and subsequent sleepiness (Wolfson, 2003), these poor sleep habits can contribute significantly to a delayed sleep onset and together contribute to the high percentage of Inadequate Sleep Hygiene Syndrome in adolescents. Poor sleep hygiene practices such as these, not only delay sleep onset directly because of their time-consuming nature but also because they may be stimulating enough (e.g. exciting content of video games) to increase alertness, interfering with natural sleep onset at the regular bedtime. Sleep loss is further aggravated in adolescents who must wake early to attend school (Wolfson et al., 2007) which in conjunction with delayed sleep times result in reduced total sleep time, that is Insufficient Sleep Syndrome. Insufficient Sleep Syndrome in many adolescents could plausibly be the result of both the biologically and socially-induced reduction of sleep time that occurs compared to pre pubescent years.

Finally, a common sleep disorder in this age group, as with younger groups is parental Limit Setting Disorder, where there is reduced parental ownership of adolescent sleep practices. With increasing age, there is decreasing parental control over adolescent sleep. Anticipatory guidance in regards to healthy sleep habits in this age group, for example in setting limits on bedtimes, has been shown to improve sleep hygiene and increase total sleep time in a recent study of Australian adolescents (Short, 2011).

In summary the most common sleep disorders across the paediatric life span are Sleep Onset Association Disorder, Inadequate Sleep Hygiene Syndrome, Insufficient Sleep Syndrome and parental Limit Setting Disorder.

\section{The Effects of Behavioural Sleep Disorders}

Treatment outcome studies where daytime performance deficits are ameliorated post intervention (Dahl et al., 1991; Minde, 2002) support the causal relationship between behavioural sleep disorders and daytime performance. Whilst the effects of behavioural sleep disorders on daytime performance, functioning 
and wellbeing are age dependent they can be generally categorised into three main areas-effects on neuropsychological function, physiological function and psychosocial function.

\section{Neuropsychological Function}

Only in recent years has it been apparent that behavioural sleep problems not related to a physiological sleep disorder are related to cognitive function and academic performance (Buckhault, 2011) in school aged children. Sleep parameters that have been implicated in deficits in these areas include reduced sleep time, inconsistent sleep wake schedules, late bed (and rise) times and reduced sleep quality (Buckhault, 2011). It is likely that these sleep problems would meet base criteria for sleep disorders described in the ICSD although they are not often classified as such.

Specifically neurocognitive functions that are impaired in children and young people with behavioural sleep disorders include worse short and long term memory performance (Blunden, 2005), selective attention and poorer executive function performance (Sadeh et al., 2002; Sadeh et al., 2003) compared to controls or good sleepers. Other studies have reported that learning and attention skills are significantly compromised in pre adolescent children with insufficient sleep (e.g., Dahl, 1996; Marcotte et al., 1998; Sadeh et al., 2000). Several studies have reported decreased memory or attentional capacity with reduced total sleep time or poorer quality sleep (Steenari, 2003). These are often translated into poorer academic performance which have been subjectively reported in children with Behavioural Sleep Disorders (Owens et al., 1998; Blunden et al., 2005; Blunden, 2010), Insufficient Sleep Syndrome (Kahn et al., 1989; Carskadon et al., 1998) and non-descript sleep disruption (Sadeh et al., 2002). Two studies have assessed the relationship between objectively defined nondescript sleep disruption and neurobehavioral function in otherwise healthy children. Sadeh et al. (2003) reported that children whose sleep was restricted to 30 minutes less than their regular sleep showed greater deficits in complex neurobehavioural tasks which were reversed when sleep returned to baseline. In a similar study, poorer sleep efficiency and longer sleep latency were related to poor performance on working memory tasks (Steenari, 2003).

The relationship between poor academic performance and insufficient sleep has been reported often in adolescents and is seen to compromise school performance with poorer learning, memory, attention and abstract thinking at a time when successful academic performance is paramount (Wolfson, 2003).

\section{Physiological Function}

Sufficient sleep is necessary for maintaining the body's homeostasis. In consequence, sleep loss has been associated with increased stress and locomotive activity, alterations in hormonal activity and body temperature and changes in cytokines and tumor necrosis factor (Kryger et al., 1994). Children with reduced sleep duration are more likely than other children to be overweight or obese (Carter, 2011) and to have changes in appetite regulation, insulin and glucose utilisation which are associated with metabolic syndrome (Spiegel et al., 1999).

Lastly, inadequate sleep duration has been shown to increase the risk of injury among school aged children. Children who slept less than 10 hours per night were more likely to suffer unintentional injury compared with longer sleepers (Valent et al., 2001). Indeed, gross motor tasks seem to be sensitive to sleep loss. Reaction time was reported as significantly impacted after 18 hours of experimental wakefulness, with balance and agility affected after considerably more sleep loss (42 hours of wakefulness) (Copes, 1972).

\section{Psychosocial Function and Behaviour}

Problematic behaviour has long been a consequence of insufficient sleep (Pearl et al., 2002; Carskadon et al., 2004; Yokomaku 2008) with sleep loss resulting in increased aggression, irritability, emotional lability and lower frustration tolerance in all age groups. It would appear that any sleep disorder that reduces either sleep quality or quantity has a detrimental effect on behaviour. This has been clearly demonstrated with respiratory sleep disorders (Chervin et al., 1997; Chervin et al., 2002; O’Brien et al., 2004; Gozal et al., 2007). However problematic behaviours are also significant in children with behavioural sleep disorders - that is, with no respiratory or physiological aetiology. These behaviours include parentally reported problematic behaviours such as irritability, emotional lability, hyperactivity (Owens et al., 1998; Minde, 2002; Blunden et al., 2005), aggression, delinquent behaviours (Smedje et al., 2001; Sadeh et al., 2002) and internalising problems (such as anxiety) (Gregory, 2005).

Interestingly, reduced total sleep time has also been associated with an increased likelihood of mood disorders (such as depression) or psychiatric disorders (such as conduct disorder and attention deficit hyperactivity disorder) (Dahl et al., 1991; Dahl, 1996; Ivanenko, 2008) although it has been suggested that these relationships are bidirectional (Dahl et al., 1991) and are likely to have other contributing factors. Certainly the association between sleep loss and depression has been clearly shown in (Hiscock et al., 2001; Hiscock, 2008).

\section{Family Function}

Behavioural sleep disorders can have significant effects on family function (Kerr et al., 1994). Those focussed on infants and pre school children have reported significant detrimental effects of poorly consolidated sleep from behavioural sleep disorders. Numerous studies have shown a strong relationship between poor sleep in young children and poor maternal wellbeing particularly maternal depression, with some studies reporting significant impacts of family function (Hiscock et al., 2001; Hiscock et al., 2007). Some reports suggest that the stress of having a child who has poor sleep and additionally consequential poor behaviour during the day has contributed to increase levels of parental discord and even child abuse (Chavin et al., 1980; Kerr et al., 1994). Maternal reports of good sleep quality attenuate this relationship as clearly, children's disrupted sleep manifestly disrupts parents sleep and resulting in sleep loss for parents. Indeed, the ICSD contains two sleep disorders which patently are focussed on the effects of poor sleep on parents-Adjustment Disorder and Limit Setting Disorder. The effects of poor sleep are additionally felt in families with lower socio-economic income levels (Buckhault, 2011), which would suggest that in households with other stressors, sleep problems in children have both a cause and effect role on the family.

\section{Mechanisms of Negative Sequelae from Behavioural Sleep Disorders}

The mechanisms by which sleep pathology, especially sleep 
deprivation and disruption, result in daytime performance deficits remain unclear, although some studies on animals are providing some information. Interestingly, some of the cellular and systemic mechanisms that have been implicated in the daytime deficits associated with intermittent hypoxia seen in respiratory sleep disorders such as sleep apnea, may also operate during sleep deprivation (Blunden et al., 2006).

For example, studies have shown that sleep deprivation- induced cellular injury (Everson, 2005), suppression of neurogenesis and long-term potentiation in the hippocampus in animal models (Silva, 2004) effect functioning of these structures that are involved in motivation, goal direction, reward, and attentional capacity (Hanlon, 2005). It has been suggested that the prefrontal cortex, control centre for executive function (Goldberg, 2002), may be compromised when sleep is less than optimal and this may account for the reduced performance in domains directed by that brain area. In fact there is evidence that sleep deprivation following a learning task reduces communication between the hippocampus and the pre-frontal cortex that ordinarily occurs during sleep (Buckhault, 2011). It has also been suggested that whilst suboptimal brain recovery with sleep loss may be a factor in daytime performance deficits, so too, sleepiness per se, due to fatigue and inability to focus on salient material, may be as important to daytime deficits as more cellular and biological mechanisms or brain pathways (Blunden, 2006).

Furthermore, while both slow wave and rapid eye movement sleep are associated with learning tasks (Buckhault, 2011) REM sleep appears to be important for more memory consolidation tasks than NREM (Plihal, 1997). REM sleep is important for emotional and procedural memory while NREM sleep is important for declarative memory (Walker et al., 2004). Behavioural sleep disorders which reduce sleep quantity consequently shortening the amount of REM sleep in the early hours of the morning, may well have a significant impact on learning capacity, due to changes in REM sleep architecture.

\section{Treatment of Behavioural Sleep Disorders}

The direction of causality, in which sleep pathology induces or contributes to daytime deficits, is supported by a number of studies on the efficacy of behavioural interventions for these sleep problems. See Table 3 for common sleep treatments options.

For infants and young children, the most common sleep disorders are those that derive from young childrens' inability to self-soothe. The American Academy of Sleep Medicine has released a standards of practice document for behavioural treatment of bedtime problems and night wakings in young children (Mindell et al., 2006). Overall, it was found that of 52 treatment studies reviewed, 94\% reported that behavioural interventions were efficacious and $80 \%$ of children treated demonstrated clinically significant improvement. Common sleep training methods reported in that paper ranged from parents leaving their child to initiate sleep alone while completely ignoring their protests or signalling cries (extinction or often called the "cry-it-out-method"), through graduated extinction or "controlled crying/comforting" where the parent checks their child with minimal interaction at increasingly longer intervals, to the most interactive model where a parent stays with their child in their room (parental presence) and/or gradually withdraws their presence, eventually leaving the room and then adopting the periodic checking paradigm (the "camping out method”).

There is evidence to suggest that these methods are all successful in reducing nighttime protests and encouraging self settling and sleeping alone without parental intervention, coupled with low relapse rates. However, reports are also common that those behavioural treatments which require some level of ignoring a child's cries, are difficult for parents to overcome (Mindell et al., 2006; Meltzer, 2010) and can result in abandonment of the process. Some authors suggest this may even be detrimental to the parent/child relationship (Scher, 1999; Murray, 2007; Cortesi, 2008). Alternative methods of behavioural sleep treatments that do not necessitate ignoring a child's cry, yet achieve similar sleep behaviour outcomes, are emerging (Blunden, 2011).

Although in older children Sleep Onset Association Disorders are also common, extinction techniques are less common. In older children, desensitisation to sleeping alone can be assisted with childhood cognitive behavioural therapy through psychological techniques of desensitisation to reduce anxiety, thereby developing a child's confidence and self esteem to sleep alone (Sadeh, 2005; Gordon, 2007). Attention to calming and regular bedtime routines in what is essentially improved sleep hygiene with a component of assisting parents in limit setting is also successful (Mindell 2009).

For adolescents, the most common sleep disorders are Insufficient Sleep Syndrome and Inadequate Sleep Hygiene Disorder. It is clear that adolescents have a biological delay in melatonin secretion which results in a delayed onset of sleepiness and subsequent later bedtimes (Carskadon, 1998). Whilst this is not a behavioural sleep disorder, it is important that the sleep patterns of adolescents be understood within this biological context. Precise history taking to estimate circadian phase based on a careful patient history can assist in deciding if the sleep onset delay is primarily biologically driven. If it is, bright light treatment on waking (to suppress melatonin), reduction of bright light in the evening (to enable the rise of melatonin) and in some cases exogenous melatonin administration are considered to be the treatments of choice for these circadian rhythm sleep disorders (Bjorvatn, 2009). Circadian phase needs to be estimated in order to time the exposure to light appropriately as inappropriately timed bright light and melatonin may likely worsen the condition. Whilst measurements of core body temperature or endogenous melatonin rhythms are seldom used in a clinical practice, estimations of circadian phase are usually undertaken during clinical history taking.

Despite the fact that sleep in adolescents is impacted by delayed melatonin onset, as noted above, a large proportion of adolescent sleep problems are also caused by or at the very least exacerbated by, lifestyle factors. Similar to instigating sleep routines in younger children (Mindell, 2009), improving basic sleep hygiene can be a successful in the first instance. Apart from individual psycho-education including maintaining regular sleep wake schedules, reducing media usage at night and the use of strategic napping, some school based sleep education programs are attempting to increase understanding and knowledge of how to minimise the effects of biologically driven changes to sleep wake patterns during adolescence (Cortesi, 2004; De Sousa, 2007; Moseley, 2009). But knowledge alone is not necessarily equating to behaviour change and this remains a challenge for those who are trying to improve sleep health in this group.

In fact, the understanding of sleep problems in the commu- 


\section{S. L. BLUNDEN}

Table 3.

Common treatment options for behavioural sleep disorders.

\begin{tabular}{ll}
\hline Behavioural sleep disorder & Treatment \\
\hline \multirow{2}{*}{ Inadequate Sleep Hygiene } & Sleep routine \\
& Psychoeducation \\
Regulate media usage \\
Parental limit setting \\
Environmental Sleep Disorder & Psychoeducation \\
& Improved sleep hygiene \\
Adjustment Sleep Disorder & Parental limit setting \\
& Support systems \\
& Sleep routine \\
Insufficient Sleep Syndrome & Improved sleep hygiene \\
& Standardisation of sleep patterns across the week. \\
Parental limit setting \\
Limit-Setting Sleep Disorder & Parental psychoeducation \\
Sleep-Onset Association Disorder & Desensitisation to allow the child to learn self soothing behaviours through behavioural sleep \\
& treatments (e.g. extinction/graduated extinction or less radical Camping out methods) \\
& Cognitive behaviour therapy for sleep related anxiety \\
\hline
\end{tabular}

nity and even amongst health professionals is low (Owens et al., 2001; Archbold et al., 2002; Blunden et al., 2004). Therefore health professionals who work with children may need to consider basic screening for sleep problems before they become problematic. Even a brief evaluation of sleep (e.g. the BEARS screener-Bedtime, Excessive Daytime Sleepiness, Awakenings, Regularity, Snoring) (Owens et al., 2005) is helpful when conducting routine clinical examinations, especially when there are concerns about a child's daytime functioning.

Finally, clear evidence exists that delaying school start times has resulted in better performance and wellbeing outcomes in adolescents and may well be considered when attempting to avoid chronic sleep loss in adolescents. However, this is logistically outside the influence of health care professionals.

\section{Conclusion}

Behavioural sleep disorders constitute a significant problem in up to $30 \%$ of children and their families and even more in adolescents. Given their high prevalence, the impact on many domains of children's development and wellbeing, the potential for ongoing sleep and broader health problems with age, coupled with significant family impact, the assumption that behavioural sleep disorders are fundamentally 'benign' would appear to be misguided. Similarly the belief that paediatric sleep disorders either are inevitably outgrown or are refractory to treatment may also need re-assessment. Indeed, given the tremendous neural, cognitive, and social changes that occur across the childhood years, increasing awareness, education and treatment options need to be considered to eliminate the impact of what is effectively very modifiable health behaviours.

\section{REFERENCES}

AASM. (2005). International classification of sleep disorders: Diagnostic and coding manual. Westchester, IL: American Academy of Sleep Medicine.

Archbold, K. H., Pituch, K. J., Panahi, P., \& Chervin, R. D. (2002). Symptoms of sleep disturbances among children at two general pediatric clinics. The Journal of Pediatrics, 140, 97-102. doi:10.1067/mpd.2002.119990

Armstrong, K., Quin, R. A., \& Dadds, M. R., (1994). The sleep patterns of normal children. The Medical Journal of Australia, 161, 202-206.
Bjorvatn, B., \& Pallesen, S. (2009). A practical approach to circadian rhythm sleep disorders. Sleep Medicine Reviews, 13, 47-60. doi:10.1016/j.smrv.2008.04.009

Blader, J., Koplewicz, H., Abikoff, H., \& Foley, C. (1997). Sleep problems of elementary school children. A community survey. Archives of Pediatric \& Adolescent Medicine, 151, 473-480. doi:10.1001/archpedi.1997.02170420043007

Blunden, S. (2011). Behavioural treatments to encourage solo sleeping in pre- school children: No need for controlled crying. Journal of Child Health Care, 15, 107-117. doi:10.1177/1367493510397623

Blunden, S., \& Chervin, R. D. (2010). Sleep, performance and behaviour in Australian indigenous and non-indigenous children: An exploratory comparison. Journal of Paediatric Child Health, 46, 10-16. doi:10.1111/j.1440-1754.2009.01610.x

Blunden, S., Hoban, T. F., \& Chervin, R. D. (2006). Sleepiness in children. Sleep Medicine Clinics, 1, 105-118. doi:10.1016/j.jsmc.2005.11.006

Blunden, S., Lushington, K., Lorenzen, B., Wong, J., Balendran, R., \& Kennedy, D. (2003). Symptoms of sleep breathing disorders in children are underreported by parents at general practice visits. Sleep Breath, 7, 167-176. doi:10.1007/s11325-003-0167-8

Blunden, S. L., \& Beebe, D. W. (2006). The contribution of intermittent hypoxia, sleep debt and sleep disruption to daytime performance deficits in children: Consideration of respiratory and non-respiratory sleep disorders. Sleep Medicine Reviews, 10, 109-118. doi:10.1016/j.smrv.2005.11.003

Blunden, S. L., Lushington, K., Lorenzen, B., Martin, J., \& Kennedy, D. (2005). Neuropsychological and psychosocial function in children with a history of snoring or behavioral sleep problems. Journal of Pediatrics, 146, 780-786. doi:10.1016/j.jpeds.2005.01.043

Blunden, S. L., Lushington, K., Lorenzen, B., Ooi, T., Fung, F., \& Kennedy, D. (2004) Are sleep problems under-recognised in general practice? Archives of Disease in Childhood, 89, 708-712. doi:10.1136/adc.2003.027011

Buckhault, J. (2011). Insufficient sleep and socioeconomic status. Child Dev Perspectives, 5, 59-65. doi:10.1111/j.1750-8606.2010.00151.x

Carskadon, M., Acebo, C., \& Jenni, O. (2004). Regulation of adolescent sleep: Implications for behavior. Annals of the New York Academy Science, 1021, 276-291. doi:10.1111/j.1750-8606.2010.00151.x

Carskadon, M., \& Wolfson, A. C. A. (1998), Adolescent sleep patterns, circadian timing, sleepiness at a transition to early school days. Sleep, 21, 871-881.

Carter, P., Taylor, B. J., Williams, S. M., \& Taylor, R. W. (2011). Longitudinal analysis of sleep in relation to BMI and body fat in children: The FLAME study. British Medicine Journal, 342, d2712.

Chaput, J. P. Bouchard, C., \& Tremblay, A. (2008). The association between sleep duration and weight gain in adults: A 6-year prospective study from the Quebec family study. Sleep, 31, 517-23. 


\section{S. L. BLUNDEN}

Chavin, W., \& Tinson, S. (1980). Children with sleep difficulties. Health Visitor, 53, 477-480.

Chervin, R., Dillon, J., Bassetti, C., Ganoczy, D., \& Pituch, K. (1997). Symptoms of sleep disorders, inattention, and hyperactivity in children. Sleep, 20, 1185-1192.

Chervin, R. D., Archbold, K. H., Dillon, J. E., Panahi, P., Pituch, K. J., Dahl, R. E., \& Guilleminault, C, (2002) Inattention, hyperactivity, and symptoms of sleep-disordered breathing. Pediatrics, 109, 449456. doi:10.1542/peds.109.3.449

Copes, K., \& Rosentweig, J. (1972). The effects of sleep deprivation on motor performance of ninth grade students. Journal of Sports Medicine, 12, 47-53.

Cortesi, F., Giannotti, F., Sebastiani, T., Bruni, \& O’Ottaviano, S. (2004). Knowledge of sleep in Italian high school students: Pilot-test of a school-based sleep educational program. The Journal of Adolescent Health, 34, 344-351.

Cortesi, F., Giannotti, F., Sebastiani, T., Vagnoni, C., \& Marioni, P., (2008). Cosleeping versus solitary sleeping in children with bedtime problems: Child emotional problems and parental distress. Behavorial Sleep Medicine, 6, 89-105. doi:10.1080/15402000801952922

Dahl, R. (1996). The impact of inadequate sleep on children's daytime cognitive function. Seminars in Pediatric Neurology, 3, 44-50. doi:10.1016/S1071-9091(96)80028-3

Dahl, R. E., Pelham, W. E., \& Wierson, M. (1991). The role of sleep disturbances in attention deficit disorder symptoms: A case study. Journal of Pediatric Psychology, 16, 229-239. doi:10.1093/jpepsy/16.2.229

De Sousa, I., Araújo, J. F., \& De Azevedo, C. V. M. (2007). The effect of a sleep hygiene education program on the sleep-wake cycle of Brazilian adolescent students. Sleep and Biological Rhythms, 5, 251258. doi:10.1111/j.1479-8425.2007.00318.x

Everson, C., Laatsch, C. D., \& Hogg, N. (2005). Antioxidant defence responses to sleep loss and sleep recovery. American Journal of Physiology Regulatory, Integrative and Comparetive Physiology, 288, R374-R383. doi:10.1152/ajpregu.00565.2004

Fallone, G., Acebo C., Arnedt, J., Seifer, R., \& Carskadon, M. (2001). Effects of acute sleep restriction on behavior, sustained attention, and response inhibition in children. Perceptual and Motor Skills, 93, 213229.

Goldberg, E. (2002). The executive brain: Frontal lobes and the civilised mind. Oxford University Press: Oxford.

Gordon, J., King, N. J., Gullone, E., Muris, P., \& Ollendick, T. H. (2007). Treatment of children's nighttime fears: The need for a modern randomised controlled trial. Clinical Psychology Reviews, 27, 98-113. doi:10.1016/j.cpr.2006.07.002

Gozal, D., \& Kheirandish-Gozal, L. (2007). Neurocognitive and behavioral morbidity in children with sleep disorders. Current Opinion in Pulmonary Medicine, 13, 505-509. doi:10.1097/MCP.0b013e3282ef6880

Gregory, A., \& Eley, T. C. (2005). Sleep problems, anxiety and cogntive style in school aged children. Infant and Child Development, 14, 435-444.

Gupta, R., Saini, D. P., Acharya, U., \& Miglani, N. (1994). Impact of television on children. Indian Journal of Pediatrics, 61, 153-159. doi:10.1007/BF02843606

Hanlon, E., Andrzejewski, M. E., Harder, B. K., Kelley, A. E., \& Benca, R. M. (2005). The effect of REM sleep deprivation on motivation for food reward. Behavioural Brain Research, 163, 58-69.

Heins, E., Seitz, C., Schüz, J., Toschke, A., Harth, K., Letzel, S., \& Böhler, E. (2007). Bedtime, television and computer habits of primary school children in Germany. Gesundheitswesen, 69, 151-157. doi:10.1055/s-2007-971061

Hiscock, H., Bayer, J. K., Hampton, A., Ukoumunne, O. C., \& Wake, M., (2008). Long-term mother and child mental health effects of a population-based infant sleep intervention: Ccluster-randomized, controlled trial. Pediatrics, 122, e621-e627. doi:10.1542/peds.2007-3783

Hiscock, H., Canterford, L., Ukoumunne, O., \& Wake, M., (2007). Adverse associations of sleep problems in Australian preschoolers: National population study. Pediatrics, 119, 86-93. doi:10.1542/peds.2006-1757
Hiscock, H., \& Wake, M., (2001). Infant sleep problems and postnatal depression: A community-based study. Pediatrics, 107, 1317-1322. doi:10.1542/peds.107.6.1317

Ivanenko, A J, K., (2008) Sleep disturbances in children with psychiatric disorders. Seminars in Pediatric Neurology, 15, 70-78. doi:10.1016/j.spen.2008.03.008

Johnson, J., Cohen, P., Kasen, S., \& Brook, J. S. (2004). Association between television viewing and sleep problems during adolescence and early adulthood. Archives of Pediatrics and Adolescent Medicine, 158, 562-568. doi:10.1001/archpedi.158.6.562

Kahn, A., Van de Merckt, C., Rebuffat, E., Mozin, M., Sottiaux, M., Blum, D., \& Hennart, P. (1989). Sleep problems in healthy preadolescents. Pediatrics, 84, 542-546.

Kerr, S., \& Jowett, S. (1994). Sleep problems in pre-school children: A review of the lieterature. Child Care Health Development, 20, 379391. doi:10.1111/j.1365-2214.1994.tb00400.x

Kryger, M., Roth, T., \& Dement, W. C. (1994). Principles and practices of sleep medicine (2nd ed.). Philadelphia: W.B. Saunders Company.

Kushnir, J., \& Sadeh, A. (2011). Assesment of a brief intervention for nighttime fears in preschool children. European Journal of Pediatrics, Article ID:21594575. doi:10.1007/s00431-001-1488-4

Laureys, S., Peigneux, P., Perrin, F., \& Maquet, P. (2002). Sleep and motor skill learning. Neuron, 35, 5-7. doi:10.1016/S0896-6273(02)00766-3

Marcotte, A., Thache,r P., Butters, M., Bortz, J., Acebo, C., \& Carskadon, M. (1998). Parental report of sleep problems in children with attentional and learning disorders. Journal of Developmental and Behavioral Pediatrics, 19, 178-186. doi:10.1097/00004703-199806000-00005

McKenna, J. (2000). Cultural influences on infant and childhood sleep biology and the science that studies it: Toward a more inclusive paradigm. In G. Loughlin, J. L. Carroll \& C. L. Marcus (Eds.), Sleep and breathing in children: A developmental approach. New York, NY: Marcel Dekker, 199-230.

Meltzer, L. (2010). Clinical management of behavioral insomnia of childhood: Treatment of bedtime problems and night wakings in young children. Behavioral Sleep Medicine, 8, 172-189. doi:10.1080/15402002.2010.487464

Minde, K. (2002). Treatment of sleep problems in small children. Acta Paediatrics, 91, 866-867. doi:10.1111/j.1651-2227.2002.tb02845.x

Mindell, J., Kuhn, B., Lewin, D., Meltzer, L., \& Sadeh, A. (2006). Behavioral treatment of bedtime problems and night wakings in infants and young children. Sleep, 29, 1263-1276.

Mindell, J., Owens, J., \& Carskadon, M. (1999). Developmental features of sleep. Child and Adolescent Psychiatric Clinics of North America, 8, 695-725.

Mindell, J., \& Owens, J. A. (2003). Sleep problems in pediatric practice: clinical issues for the pediatric nurse practitioner. Journal of Pediatric Health Care, 17, 324-331.

Mindell, J., Telofski, L. S., Weigand, B., \& Kurtz, E. (2009). A nightly bedtime routine: Impact on sleep in young children and maternal mood. Sleep, 32, 599-606.

Moore, P. J., Adler, N. E., Williams, D. R., \& Jackson, J. S. (2002). Socioeconomic status and health: The role of sleep. Psychosomatic Medicine, 64, 337-344.

Morgenthaler, T., Owens, J., Alessi, C., Boehlecke, B., Brown, T. M., Coleman, J. Jr., Friedman, L., Kapur, V. K., Lee-Chiong, T., Pancer, J., \& Swick, T. J. (2006). Practice parameters for behavioral treatment of bedtime problems and night wakings in infants and young childre. Sleep, 29, 1277-1281.

Moseley, L., \& Gradisar, M. (2009). Evaluation of a school-based intervention for adolescent sleep problems. Sleep, 32, 334-341.

Murray, L., \& Ramchandani, P. (2007). Infant sleep problems: Might prevention be better than cure? Archives of Diseases in Childhood, 92, 943-944. doi:10.1136/adc.2007.124628

O'Brien, L. M., Mervis C. B., Holbrook C. R., Bruner J. L., Smith N. H., McNally, N., McClimment, M. C., \& Gozal, D. (2004). Neurobehavioral correlates of sleep-disordered breathing in children. Journal of Sleep Research, 13, 165-172. doi:10.1111/j.1365-2869.2004.00395.x 


\section{S. L. BLUNDEN}

Olds, T., Ridley, K., \& Dollman, J. (2006). Screenieboppers and extreme screenies: The place of screen time in the time budgets of 10 13 year-old Australian children. Australian and New Zealand Journal of Public Health, 30, 137-142. doi:10.1111/j.1467-842X.2006.tb00106.x

Owens-Stively, J., Frank, N., Smith, A., Hagino, O., Spirito, A., Arrigan, M., \& Alario, A. (1997). Child temperament, parenting discipline style, and daytime behavior in childhood sleep disorders. Journal of Developmental and Behavioral Pediatrics, 18, 314-321. doi:10.1097/00004703-199710000-00005

Owens, J., \& Dalzell, V. (2005). Use of the "BEARS” sleep screening tool in a pediatric residents' continuity clinic: A pilot study. Sleep Medicine, 6, 63-69. doi:10.1016/j.sleep.2004.07.015

Owens, J, Maxim, R., McGuinn, M., N =obile, C., Msall, M., \& Alario, A. (1999). Television viewing habits and sleep disturbance in school aged children. Pediatrics, 104, e27-e41. doi:10.1542/peds.104.3.e27

Owens, J., Opipari, L., Nobile, C., \& Spirito, A. (1998). Sleep and daytime behavior in children with obstructive sleep apnea and behavioral sleep disorders. Pediatrics, 102, 1178-1184. doi:10.1542/peds.102.5.1178

Owens, J., Veasey, S., \& Rosen, R. (2001). Physician, heal thyself: sleep, fatigue, and medical education. Sleep, 24, 493-495.

Pearl, P., Efron, L., \& Stein, M. (2002). Children, sleep and behaviour: A complex association. Minerva Pedaitrica, 54, 79-91.

Plihal, W., \& Born, J. (1997). Effects of early and late nocturnal sleep on declarative and porcedural memory. Journal of Cognitive Neuroscience, 9, 534-547. doi:10.1162/jocn.1997.9.4.534

Sadeh, A. (2005). Cognitive-behavioral treatment for childhood sleep disorders. Clinical Psychology Review, 25, 612-628. doi:10.1016/j.cpr.2005.04.006

Sadeh, A., Gruber, R., \& Raviv, A. (2002). Sleep, neurobehavioral functioning, and behavior problems in school-age children. Child Development, 73, 405-417. doi:10.1111/1467-8624.00414

Sadeh, A., Gruber, R., \& Raviv, A. (2003). The effects of sleep restriction and extension on school-age children: What a difference an hour makes. Child Development, 74, 444-455. doi:10.1111/1467-8624.7402008

Sadeh, A., Raviv, A., \& Gruber, R. (2000). Sleep patterns and sleep disruptions in school-age children. Developmental Psychology, 36, 291-301. doi:10.1037/0012-1649.36.3.291

Sadeh, A., Raviv, A., \& Gruber, R. (2000). Sleep patterns and sleep disruptions in school-age children. Developmental Psychology, 36, 291-301. doi:10.1037/0012-1649.36.3.291

Scher, A., \&Blumberg, O. (1999). Night waking among 1-year-olds: A study of maternal separation anxiety. Child Care Health and Development, 25, 323-334.

Sekine, M., Chandola, T., Martikainen, P., McGeoghegan, D., Marmot, M., \& Kagamimori, S. (2006). Explaining social inequalities in health by sleep: The Japanese civil servants study. Journal of Public Health, 28, 63-67. doi:10.1093/pubmed/fdi067

Short, M., Gradisar, M., Wright, H., Lack, L. C., Dohnt, H., \& Carskadon, M. A. (2011). Time for bed: parent-set bedtimes associated with improved sleep and daytime functioning in adolescents. Sleep, 34, 797-800.
Silva, R., Abilio, V. C., Takatsu, A. L., Kameda, S. R., Grassl, C., Chehin, A. B. et al. (2004). Role of hippocampal oxidative stress in memory deficits induced by sleep deprivation in mice. Neuropharmacology, 46, 895-903. doi:10.1016/j.neuropharm.2003.11.032

Smedje, H., Broman, J., \& Hetta, J., (2001). Associations between disturbed sleep and behavioural difficulties in 635 children aged six to eight years: a study based on parents' perceptions. European Child Adolescent Psychiatry, 10, 1-9. doi:10.1007/s007870170041

Spiegel, K, Leproult, R., \& Van Cauter, E. (1999). Impact of sleep debt on metabolic and endocrine function. Lancet, 354, 1435-1439. doi:10.1016/S0140-6736(99)01376-8

Steenari, M.-R., Vuontela, V., Paavonen, E., Julia, A., Carlson, S., Fjallberg, M., \& Aronen, E. T. (2003). Working memory and sleep in 6- to 13-year-old schoolchildren. American Academy of Child and Adolescent Psychiatry, 42, 85-92. doi:10.1097/00004583-200301000-00014

Stores, G. (1999). Children's sleep disorders: Modern approaches, developmental effects, and children at risk. Development Medicine \& Child Neurology, 41, 568-573. doi:10.1017/S001216229900119X

Valent, F., Brusaferro, S., \& Barbone, F. (2001). A case crossover study of sleep and childhood injury. Pediatrics, 107, E23. doi:10.1542/peds.107.2.e23

Van den Bulck, J. (2004). Television viewing, computer game playing and internet use and self reported time in bed and time out of bed in secondary school children. Sleep, 27, 101-104.

Vgontzas, A. N., Papaliaga, H.-M., Calhoun, M., S. Calhoun, Vela-Bueno, A., Chrousos, G. P., \& Bixler, E. O. (2008). Short sleep duration and obesity: the role of emotinal stress and sleep disturbances. International Journal of Obesity, 32, 801-809.

Walker, M., \& Stickgold, R. (2004). Sleep-dependent learning and memory consolidation. Neuron, 44, 121-133. doi:10.1016/j.neuron.2004.08.031

Weissbluth, M. (1984). Sleep duration, temperament, and Conners' ratings of three-year-old children. Journal of Developmental and $\mathrm{Be}$ havioral Pediatrics, 5, 120-123.

Wojnar, M., Ilgen, M. A., Wojnar, J., McCammon, R. J., Valenstein, M., \& Brower, K. J. (2009). Sleep problems and suicidality in the National Comorbidity Survey Replication. Journal of Psychiatric Research, 43, 526-531. doi:10.1016/j.jpsychires.2008.07.006

Wolfson, A., Spaulding, N., Dandrow, C., \& Baroni, E. (2007). Middle school start times: The importance of a good night's sleep for young adolescents. Behavioral Sleep Medicine, 5, 194-209.

Wolfson, A. R., \& Carskadon, M. A. (2003). Understanding adolescents' sleep patterns and school performance: A critical appraisal. Sleep Medicine Reviews, 7, 491-506. doi:10.1016/S1087-0792(03)90003-7

Wong, M, Brower, K., Fitzgerald, H., \& Zucker, R. (2004). Sleep problems in early childhood and early onset of alcohol and other drug use in adolescence. Alcoholism, Clinical and Experimental Research, 28, 578-587. doi:10.1097/01.ALC.0000121651.75952.39

Yokomaku, A. M., Misao, K., Omoto, F. Yamagishi, R., Tanaka, K. Takada, K., \& Kohyama, J. (2008). A study of the association between sleep habits and problematic behaviours in preschool children. Chronoboilogy International, 25, 549-564. 